\author{
Władysław Koc \\ Prof. dr hab. inż. \\ Politechnika Gdańska \\ Katedra Transportu Szynowego i Mostów \\ kocwl@pg.edu.pl
}

DOI: 10.35117/A_ENG_21_08_03

\title{
Shaping the turnout diverging track with nonlinear curvature for enhanced speed
}

\begin{abstract}
In the paper an attempt has been made to concentrate attention on shaping the variable curvature in the diverging track of the railway turnout. Making use of some earlier studies, solutions provided with a circular arc in the mid-zone, and in the extreme regions with segments of nonlinear curvature of equal length and zero curvature at the start and end of the turnout, have been assumed as models. The most advantageous choice of the type of curvature has been made taking into account the kinematic conditions. A presentation made includes an analytical record of the curvature and the tangent inclination angle in the diverging track length and the Cartesian coordinates of the track. The final part of the paper referred to the determination of a set of some basic magnitudes relating to geometric parameters appropriate for a given speed of trains and adequate to ensure the minimization of the length of the entire turnout at a given final ordinate.
\end{abstract}

Keywords: Railway turnouts; Diverging track; Curvature modelling; Selection of geometrical parameters

\section{Introduction}

The issue of railway turnouts is developed in many publications [1, 2, 4, 18, 21, 23, 24], often referring to high-speed railways $[3,20,25,26]$. The design of the turnout itself undergoes constant modifications, however, still in the typical geometric shape of the turning track in the ordinary turnout, a single circular arc without transition curves is used. Such a solution is not used on railway routes and means the necessity to limit the speed of trains. This is due to the occurrence of places of rapid, abrupt changes in the ordinates of the curvature plot at the beginning and end of the turnout. Recently, in some countries, especially on high-speed railways, efforts are being made to smooth out the curvature curve in these regions. This is achieved by introducing the so-called "Sections of clothoid" on both sides of the circular arc, on which the curvature changes in a linear manner, but often without reaching the extreme zero values [2, 3, 20, 25].

Here, the length of the turning path is divided into three zones (Fig. 1):

- an initial zone of length 11 having a linear curvature,

- a central zone of length I2 having a predetermined curvature,

- an end zone of length 13 having a linear curvature.

The kinematic parameters determine the value of the radius of the circular arc (i.e. the curvature k2) and the length of sections with variable curvature for the given train speed. Of course, various variants of solutions are possible, related to the curvature values and the lengths of the individual zones. It also allows for free shaping of the turnout bevel and its end elevation.

The work [8] presents the analytical solution of the problem for the discussed case. The equations of curvature $k(l)$ and the angle of the tangent slope $\Theta(l)$ were determined, where the parameter $l$ determines the position of a given point on the length of the curve. On this basis, the parametric equations $x(l)$ and $y(l)$ were determined for the initial zone and the end zone, 
and the equation $y(x)$ for the middle zone (i.e. circular arc). Using these equations, it is possible to determine the characteristics of any turnout with sections of linear curvature.

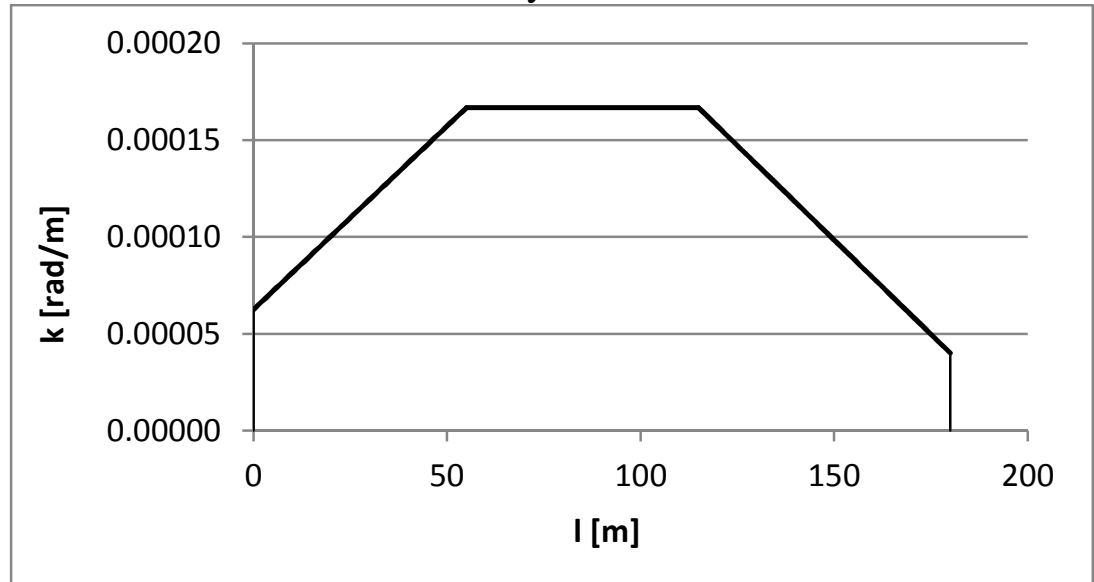

1. Curvature diagram with sections of linear curvature along the turnout return track length $\left(R_{1}=16000 \mathrm{~m}, l_{1}=55 \mathrm{~m}, R_{2}=6000 \mathrm{~m}, l_{2}=60 \mathrm{~m}, l_{3}=65 \mathrm{~m}, R_{3}=25000 \mathrm{~m}\right)$ [8]

This allowed, among other things, to clarify the issue of the geometrical configuration of two selected turnouts manufactured by Voestalpine [20]:

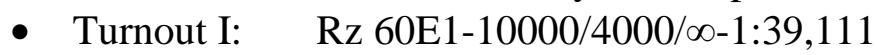

$R_{1}=10000 \mathrm{~m}, l_{1}=37,500 \mathrm{~m}, R_{2}=4000 \mathrm{~m}, l_{2}=48,383 \mathrm{~m}, l_{3}=55,225 \mathrm{~m}, R_{3}=\infty$

- Turnout II: Rz 60E1-16000/6100/œ-1:47,833

$R_{1}=16000 \mathrm{~m}, l_{1}=56,000 \mathrm{~m}, R_{2}=6100 \mathrm{~m}, l_{2}=58,0624 \mathrm{~m}, l_{3}=62,500 \mathrm{~m}, R_{3}=\infty$

The results of calculations of the characteristic values of both turnouts are shown in Table 1, and the diagrams of horizontal ordinates are shown in Figure 2.

Tab. 1. List of characteristic values for selected turnouts

\begin{tabular}{llllllllll} 
& $l=l_{1}$ & \multicolumn{9}{c}{$l=l_{1}+l_{2}$} & & $l=l_{1}+l_{2}+l_{3}$ \\
& & & \multicolumn{9}{c}{} & & \\
& $x(l)$ & $y(l)$ & $\Theta(l)$ & $x(l)$ & $y(l)$ & $\Theta(l)$ & $x(l)$ & $y(l)$ & $\Theta(l)$ \\
& {$[\mathrm{m}]$} & {$[\mathrm{m}]$} & {$[\mathrm{rad}]$} & {$[\mathrm{m}]$} & {$[\mathrm{m}]$} & {$[\mathrm{rad}]$} & {$[\mathrm{m}]$} & {$[\mathrm{m}]$} & {$[\mathrm{rad}]$} \\
I & 37,499 & 0,105 & 0,00656 & 85,878 & 0,716 & 0,01866 & 141,088 & 2,000 & 0,02556 \\
II & 55,999 & 0,151 & 0,00634 & 114,058 & 0,795 & 0,01586 & 176,546 & 2,000 & 0,02098
\end{tabular}

In the examples shown, we deal with a situation where the curvature at the end of the geometrical system takes the value of zero. Therefore, the solution presented in [8] also covers such special cases. The obtained final ordinate $y_{\mathrm{k}}=2,000 \mathrm{~m}$ indicates that both turnouts are intended for use in connections of parallel tracks on the route, the spacing of which is $4 \mathrm{~m}$. The paper [8] also presents a method of creating given geometric solutions obtaining a specific turnout slope and a specific end elevation of the turning track.

At the 10th Scientific and Technical Conference "Design, construction and maintenance of infrastructure in rail transport" INFRASZYN 2017, a modification of the discussed solution was presented, consisting of an analytical solution of the problem while alleviating the curvature in the extreme zones of the turnout [11].

Figure 3 shows a graph of curvature along the length of a turnout return track with sections of non-linear curvature, and the numerical characteristics corresponding to the turnout in Figure 1. 


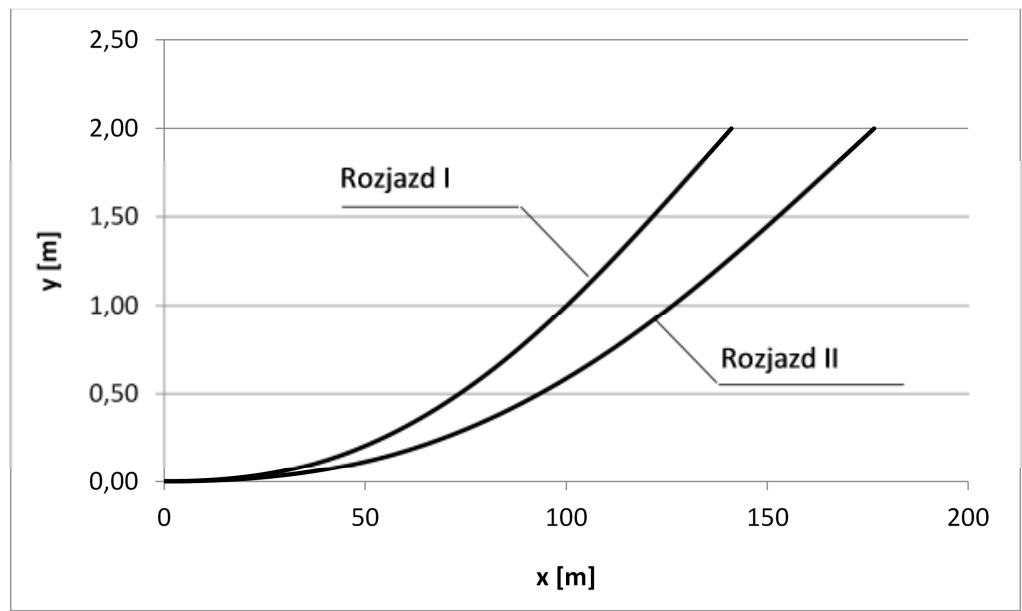

2. Graphs of horizontal ordinates along the length of the return track of turnouts I and II from Table 1 (on a contaminated scale) [8]

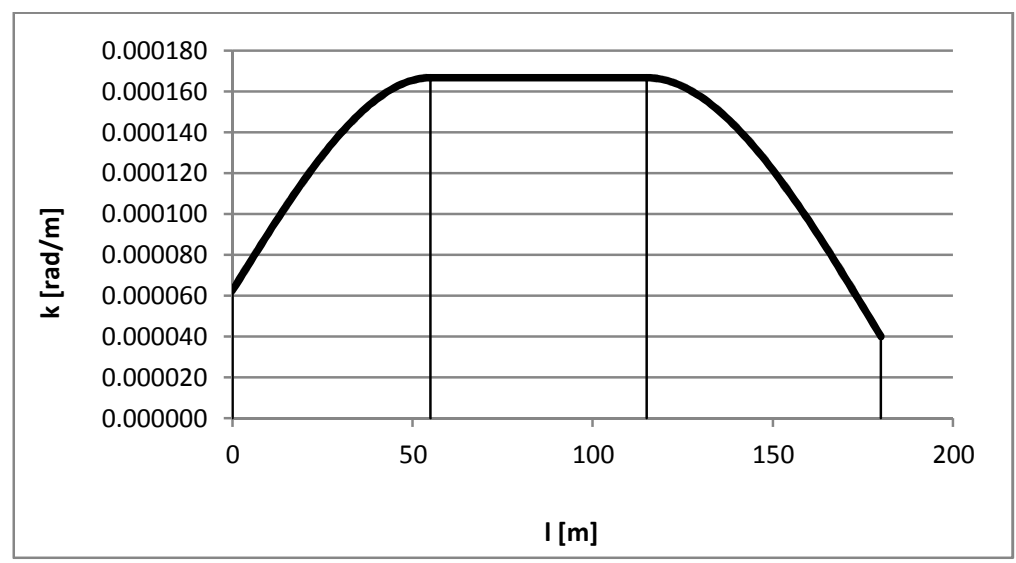

3. Curvature plot with sections of non-linear curvature along the turnout return track length $\left(R_{1}=16000 \mathrm{~m}, l_{1}=55 \mathrm{~m}, R_{2}=6000 \mathrm{~m}, l_{2}=60 \mathrm{~m}, l_{3}=65 \mathrm{~m}, R_{3}=25000 \mathrm{~m}\right)$ [11]

The comparative analysis covers the general cases appearing in Figures $\mathbf{1}$ and $\mathbf{3}$ as well as the corresponding cases with zero curvature on both sides of the system, arising after the adoption of $k_{1}=k_{3}=0$. The list of these cases was as follows:

- turnout I (with sections of linear curvature)

$R_{1}=16000 \mathrm{~m}, l_{1}=55 \mathrm{~m}, R_{2}=6000 \mathrm{~m}, l_{2}=60 \mathrm{~m}, l_{3}=65 \mathrm{~m}, R_{3}=25000 \mathrm{~m}$,

- turnout II (with sections of linear curvature)

$R_{1}=\infty, l_{1}=55 \mathrm{~m}, R_{2}=6000 \mathrm{~m}, l_{2}=60 \mathrm{~m}, l_{3}=65 \mathrm{~m}, R_{3}=\infty$,

- turnout III (with sections of nonlinear curvature)

$R_{1}=16000 \mathrm{~m}, l_{1}=55 \mathrm{~m}, R_{2}=6000 \mathrm{~m}, l_{2}=60 \mathrm{~m}, l_{3}=65 \mathrm{~m}, R_{3}=25000 \mathrm{~m}$,

- turnout IV (with sections of nonlinear curvature)

$R_{1}=\infty, l_{1}=55 \mathrm{~m}, R_{2}=6000 \mathrm{~m}, l_{2}=60 \mathrm{~m}, l_{3}=65 \mathrm{~m}, R_{3}=\infty$.

Collective diagrams of the turn track curvature along the length of the mentioned turnouts are shown in Figure 4.

The discussed issues were also taken up in the works $[9,10,12,13]$. 


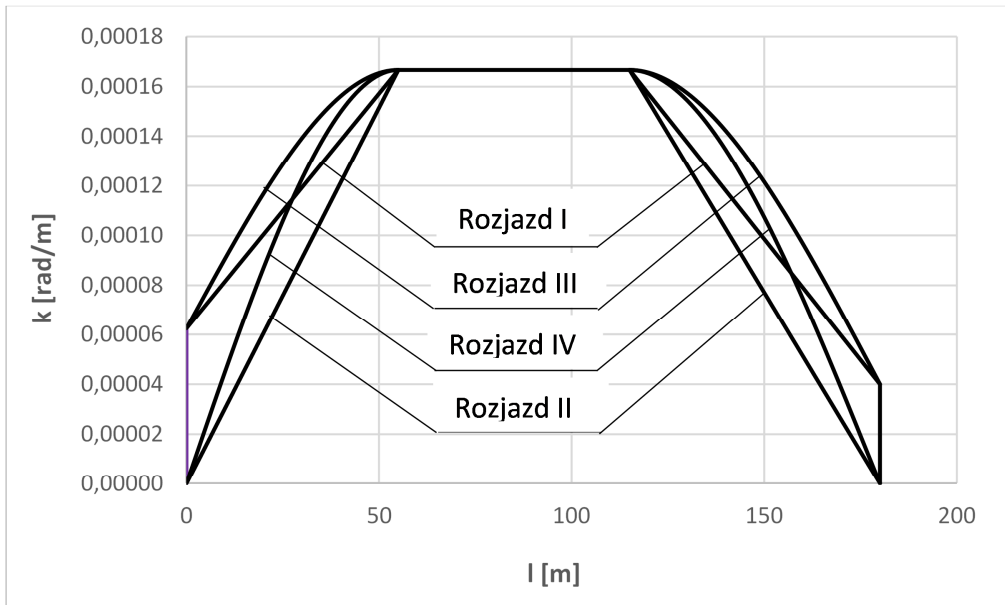

4. Diagrams of curvature along the length of the turning track of the compared turnouts $\left(R_{1}=16000 \mathrm{~m}, l_{1}=55 \mathrm{~m}, R_{2}=6000 \mathrm{~m}, l_{2}=60 \mathrm{~m}, l_{3}=65 \mathrm{~m}, R_{3}=25000 \mathrm{~m}\right)[11]$

\section{Searching for the most advantageous solution}

At this point, however, a key question arises: what set of values characterizing the considered turnout, i.e. $k_{1}, k_{2}$, and $k_{3}$ as well as $l_{1}, l_{2}$ and $l_{3}$, is the most favorable in a given situation? The number of possible variants is significantly limited by the dynamic analysis presented in the works $[16,17]$.

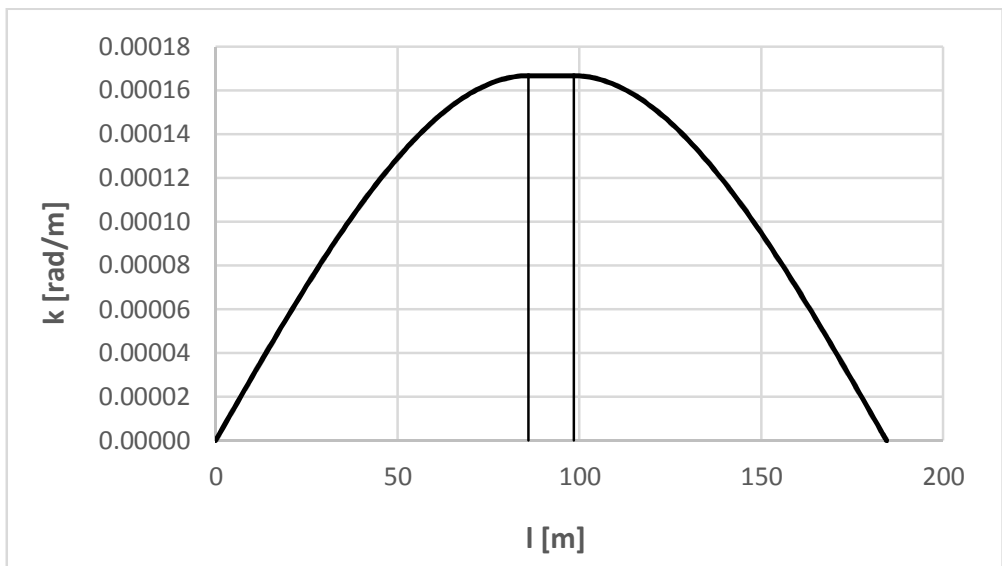

5. A favorable curve of curvature with non-linear sections along the length of the turnout return track $\left(k_{1}=0, l_{1}=86 \mathrm{~m}, k_{2}=1 / 6000 \mathrm{rad} / \mathrm{m}, l_{2}=12,484 \mathrm{~m}, l_{3}=86 \mathrm{~m}, k_{3}=0\right)$ [17]

In this analysis, several cases of using sections of linear and non-linear curvature were considered. The case with non-linear curvature sections of equal length and zero curvature at the beginning and end of the turnout turned out to be the most advantageous solution, i.e. with the lowest values of dynamic interactions (accelerations). Figure $\mathbf{5}$ shows an example of the curvature curve along the length of the turnout return track for this particular case.

Compared to the model diagrams in Figures $\mathbf{1}$ and 3, the number of control quantities in Figure $\mathbf{5}$ has decreased by half. Here, it is also possible to modify the division of the turnout return track into individual zones:

- an initial zone that has the length $l_{1}$ and curvature that varies nonlinearly from zero to value $k=1 / R$,

- a central zone that has a length $l_{2}$ and a predetermined curvature of value $k=1 / R$,

- an end zone, which has the length $l_{1}$ and curvature that varies non-linearly from $k=$ $1 / R$ to zero. 
This paper presents a complete solution to the discussed problem. This required the determination of the nature of the curvature variability in the extreme zones of the turnout turn track. Modeling sections of variable curvature along the length of the turnout return track allows creating its analytical record in the form of the $k(l)$ function. The next step is to determine a set of numerical values $R, l_{1}$ and $l_{2}$, corresponding to the set train speed and ensuring the minimization of the length of the entire turnout (at the given final ordinate).

The coordinate equations of the searched connection can be written in a parametric form [5]:

$$
\begin{gathered}
x(l)=\int \cos \Theta(l) d l \\
y(l)=\int \sin \Theta(l) d l
\end{gathered}
$$

\section{Analytical solution to the problem}

\section{A solution to the problem for the initial zone}

The use of sections of nonlinear curvature means that the following boundary conditions apply in the initial zone (for $l \in\left\langle 0, l_{1}\right\rangle$ ):

$$
k^{\prime}(0)=C \frac{k}{l_{1}} \quad\left\{\begin{array}{l}
k(0)=0 \\
k^{\prime}\left(l_{1}\right)=0
\end{array}\right.
$$

and the differential equation

$$
k^{(4)}(l)=0
$$

with a numerical factor $C \geq 0$.

As a result of solving the differential problem (3), (4) we obtain the following curvature equation:

$$
k(l)=\frac{C k}{l_{1}} l-\frac{(2 C-3) k}{l_{1}^{2}} l^{2}+\frac{(C-2) k}{l_{1}^{3}} l^{3}
$$

and a function of the angle of the tangent $\Theta(l)$ is described by the relation

$$
\Theta(l)=\frac{C k}{2 l_{1}} l^{2}-\frac{(2 C-3) k}{3 l_{1}^{2}} l^{3}+\frac{(C-2) k}{4 l_{1}^{3}} l^{4}
$$

At the end of the starting zone $\Theta\left(l_{1}\right)=\frac{6+C}{12} k l_{1}$.

The issue of the selection of the $C$ coefficient value was considered in [12]. When selecting the most favorable of the parametric curves, first of all, one should follow the criterion of the minimum required length, limited by the permissible value of the acceleration increment. For $C=0$ (which case corresponds to the Bloss curve), the length of the end segment must be $50 \%$ longer than that for the linear curvature. On the other hand, the smallest 
value of elongation (only by $1 / 3$ ) occurs for $C=1$. Taking such a value of the $C$ coefficient leads to the following equations of the functions $k(l)$ and $\Theta(l)$ for the initial zone:

$$
\begin{gathered}
k(l)=\frac{k}{l_{1}} l+\frac{k}{l_{1}^{2}} l^{2}-\frac{k}{l_{1}^{3}} l^{3} \\
\Theta(l)=\frac{k}{2 l_{1}} l^{2}+\frac{k}{3 l_{1}^{2}} l^{3}-\frac{k}{4 l_{1}^{3}} l^{4}
\end{gathered}
$$

The function $\Theta(l)$ makes it possible to determine the parametric equations $x(l)$ and $y(l)$ for this zone by using the dependencies (1) and (2). The Maxim program [19] was used to expand functions $\cos \Theta(l)$ and $\sin \Theta(l)$ into the Maclaurin series, and then individual terms were integrated, obtaining the following parametric equations:

$$
\begin{gathered}
x(l)=l-\frac{k^{2}}{40 l_{1}^{2}} l^{5}-\frac{k^{2}}{36 l_{1}^{3}} l^{6}+\frac{5 k^{2}}{504 l_{1}^{4}} l^{7}+\frac{k^{2}}{96 l_{1}^{5}} l^{8}+\left(\frac{k^{4}}{3456 l_{1}^{4}}-\frac{3 k^{2}}{864 l_{1}^{6}}\right) l^{9} \\
y(l)=\frac{k}{6 l_{1}} l^{3}+\frac{k}{12 l_{1}^{2}} l^{4}-\frac{k}{20 l_{1}^{3}} l^{5}-\frac{k^{3}}{336 l_{1}^{3}} l^{7}-\frac{k^{3}}{192 l_{1}^{4}} l^{8}+\frac{k^{3}}{2592 l_{1}^{5}} l^{9}
\end{gathered}
$$

At the end of the zone, the angle of the tangent $\Theta\left(l_{1}\right)=\frac{7}{12} k l_{1}$.

It should be noted here that the presented solution corresponds to the new form of the transition curve, adapted to the railway operational requirements, which was proposed in the works $[14,15]$.

\section{A solution to the problem of middle zone}

In the zone of the circular arc, i.e. for $l \in\left\langle l_{1}, l_{1}+l_{2}\right\rangle$ there is a constant curvature

$$
k(l)=k
$$

and function $\Theta(l)$ is described by the relation

$$
\Theta(l)=\frac{(C-6) k}{12} l_{1}+k l
$$

Value of the angle at the end of a circular arc $\Theta(l)$ equals $\Theta\left(l_{1}+l_{2}\right)=\frac{6+C}{12} k l_{1}+k l_{2}$; for coefficient $C=1$ value

$$
\Theta\left(l_{1}+l_{2}\right)=\frac{7}{12} k l_{1}+k l_{2}
$$

The circular arc equation can be written as an explicit function $y(x)$. The method of its determination is analogous to that in the works $[6,7]$. We assume the length of the circular arc 
$l_{2}$ (measured along the arc itself). Its radius is $R$ and the slope of the tangent at the starting point $s_{1}=\tan \Theta\left(l_{1}\right)$. First, we determine the coordinates of the arc's center-point $S\left(x_{S}, y_{S}\right)$.

$$
\begin{gathered}
x_{S}=x\left(l_{1}\right)-\frac{s_{1}}{\sqrt{1+s_{1}^{2}}} R \\
y_{S}=y\left(l_{1}\right)+\frac{1}{\sqrt{1+s_{1}^{2}}} R
\end{gathered}
$$

The circular arc equation is as follows:

$$
y(x)=y_{S}-\sqrt{R^{2}-\left(x_{s}-x\right)^{2}} \quad, \quad x \in\left\langle x\left(l_{1}\right), x\left(l_{1}+l_{2}\right)\right\rangle
$$

Since the angle of return of the tangents of a circular arc is $\alpha=l_{2} / R$, formula for the angle of inclination of the tangent to the arc at its end, i.e. for $x\left(l_{1}+l_{2}\right)$, can also be taken as $\Theta\left(l_{1}+l_{2}\right)=\Theta\left(l_{1}\right)+\alpha$. The result is the slope of the tangent at this point $s_{2}=\tan \left[\Theta\left(l_{1}\right)+\alpha\right]$. The coordinates of the end of a circular arc are as follows:

$$
\begin{aligned}
& x\left(l_{1}+l_{2}\right)=x\left(l_{1}\right)+\tan \frac{\alpha}{2}\left(\frac{1}{\sqrt{1+s_{1}^{2}}}+\frac{1}{\sqrt{1+s_{2}^{2}}}\right) R \\
& y\left(l_{1}+l_{2}\right)=y\left(l_{1}\right)+\tan \frac{\alpha}{2}\left(\frac{s_{1}}{\sqrt{1+s_{1}^{2}}}+\frac{s_{2}}{\sqrt{1+s_{2}^{2}}}\right) R
\end{aligned}
$$

\section{A solution to the problem for the end zone}

We assume boundary conditions

$$
\begin{cases}k\left(l_{1}+l_{2}\right)=k & k\left(2 l_{1}+l_{2}\right)=0 \\ k^{\prime}\left(l_{1}+l_{2}\right)=0 & k^{\prime}\left(2 l_{1}+l_{2}\right)=-C \frac{k}{l_{1}}\end{cases}
$$

and differential equation (4). The solution of the differential problem (4), (18) is as follows:

where

$$
\begin{gathered}
k(l)=c_{1}+c_{2} l+c_{3} l^{2}+c_{4} l^{3} \\
c_{1}=\left[1-\frac{3-C}{l_{1}^{2}}\left(l_{1}+l_{2}\right)^{2}-\frac{2-C}{l_{1}^{3}}\left(l_{1}+l_{2}\right)^{3}\right] k \\
c_{2}=\left[\frac{2(3-C)}{l_{1}^{2}}\left(l_{1}+l_{2}\right)-\frac{3(2-C)}{l_{1}^{3}}\left(l_{1}+l_{2}\right)^{2}\right] k
\end{gathered}
$$




$$
\begin{aligned}
& c_{3}=-\left[\frac{3-C}{l_{1}^{2}}+\frac{3(2-C)}{l_{1}^{3}}\left(l_{1}+l_{2}\right)\right] k \\
& c_{4}=\frac{2-C}{l_{1}^{3}} k
\end{aligned}
$$

The equation for the angle of the tangent has the form

$$
\begin{array}{r}
\Theta(l)=c_{0}+c_{1} l+\frac{1}{2} c_{2} l^{2}+\frac{1}{3} c_{3} l^{3}+\frac{1}{4} c_{4} l^{4} \\
c_{0}=\left[\frac{C-6}{12} l_{1}+\frac{3-C}{3 l_{1}^{2}}\left(l_{1}+l_{2}\right)^{3}+\frac{2-C}{4 l_{1}^{3}}\left(l_{1}+l_{2}\right)^{4}\right] k
\end{array}
$$

where

At the end of the curve, the value of the angle $\Theta(l)$ is $\Theta\left(2 l_{1}+l_{2}\right)=\frac{6+C}{6} k l_{1}+k l_{2}$; for coefficient

$C=1$ value

$$
\Theta\left(2 l_{1}+l_{2}\right)=\frac{7}{6} k l_{1}+k l_{2}
$$

For $C=1$ the values of the numerical coefficients are:

$$
\begin{aligned}
& c_{0}=\left[-\frac{5}{12} l_{1}+\frac{2}{3 l_{1}^{2}}\left(l_{1}+l_{2}\right)^{3}+\frac{1}{4 l_{1}^{3}}\left(l_{1}+l_{2}\right)^{4}\right] k \\
& c_{1}=\left[1-\frac{2}{l_{1}^{2}}\left(l_{1}+l_{2}\right)^{2}-\frac{1}{l_{1}^{3}}\left(l_{1}+l_{2}\right)^{3}\right] k \\
& c_{2}=\left[\frac{4}{l_{1}^{2}}\left(l_{1}+l_{2}\right)-\frac{3}{l_{1}^{3}}\left(l_{1}+l_{2}\right)^{2}\right] k \\
& c_{3}=-\left[\frac{2}{l_{1}^{2}}+\frac{3}{l_{1}^{3}}\left(l_{1}+l_{2}\right)\right] k \\
& c_{4}=\frac{1}{l_{1}^{3}} k
\end{aligned}
$$

After expanding the function $\cos \Theta(l)$ and $\sin \Theta(l)$ into a Taylor series using the Maxim program [19] and integrating individual words, we obtain parametric equations:

$$
\begin{aligned}
x(l) & =x\left(l_{0}\right)+\cos \Theta_{0}\left(l-l_{0}\right)-\frac{k}{2} \sin \Theta_{0}\left(l-l_{0}\right)^{2}-\frac{k^{2}}{6} \cos \Theta_{0}\left(l-l_{0}\right)^{3} \\
& +\frac{k^{3}}{24} \sin \Theta_{0}\left(l-l_{0}\right)^{4}+\frac{k^{4}}{120} \cos \Theta_{0}\left(l-l_{0}\right)^{5} \\
y(l) & =y\left(l_{0}\right)+\sin \Theta_{0}\left(l-l_{0}\right)+\frac{k}{2} \cos \Theta_{0}\left(l-l_{0}\right)^{2}-\frac{k^{2}}{6} \sin \Theta_{0}\left(l-l_{0}\right)^{3}
\end{aligned}
$$




$$
-\frac{k^{3}}{24} \cos \Theta_{0}\left(l-l_{0}\right)^{4}+\frac{k^{4}}{120} \sin \Theta_{0}\left(l-l_{0}\right)^{5}
$$

where $l_{0}=l_{1}+l_{2}, \quad \quad \Theta_{0}=\Theta\left(l_{1}+l_{2}\right)$.

The basic relation for each turnout applies

$$
\tan \Theta\left(2 l_{1}+l_{2}\right)=\frac{1}{n}
$$

\section{Analysis of the radius of a circular arc}

Tab. 2. Summary of the values characteristic for the generated variants with increasing the

\begin{tabular}{|c|c|c|c|c|c|c|c|}
\hline $\begin{array}{l}R \\
{[\mathrm{~m}]}\end{array}$ & $\begin{array}{l}l_{1} \\
{[\mathrm{~m}]}\end{array}$ & $\begin{array}{l}l_{2} \\
{[\mathrm{~m}]}\end{array}$ & $\begin{array}{l}l_{\mathrm{k}} \\
{[\mathrm{m}]}\end{array}$ & $\begin{array}{c}\Theta\left(l_{\mathrm{k}}\right) \\
{[\mathrm{rd}]}\end{array}$ & $n$ & $\begin{array}{l}x\left(l_{\mathrm{k}}\right) \\
{[\mathrm{m}]}\end{array}$ & $\begin{array}{l}y\left(l_{\mathrm{k}}\right) \\
{[\mathrm{m}]}\end{array}$ \\
\hline 1800 & 146 & 0 & 292 & 0,09463 & 10,53595 & 291,362 & 15,177 \\
\hline 2000 & 131 & 0 & 262 & 0,07642 & 13,06067 & 261,627 & 11,002 \\
\hline 2200 & 119 & 0 & 238 & 0,06319 & 15,82530 & 237,769 & 8,256 \\
\hline 2400 & 109 & 0 & 218 & 0,05299 & 18,85520 & 217,851 & 6,350 \\
\hline 2600 & 101 & 0 & 202 & 0,04532 & 22,04995 & 201,899 & 5,034 \\
\hline 2800 & 94 & 0 & 188 & 0,03917 & 25,51886 & 187,930 & 4,049 \\
\hline 3000 & 88 & 0 & 176 & 0,03422 & 29,20937 & 175,950 & 3,312 \\
\hline 3200 & 82 & 0 & 164 & 0,02990 & 33,43951 & 163,964 & 2,696 \\
\hline 3400 & 77 & 0 & 154 & 0,02642 & 37,83906 & 153,974 & 2,238 \\
\hline 3600 & 73 & 0 & 146 & 0,02366 & 42,26217 & 145,980 & 1,900 \\
\hline 3800 & 69 & 0 & 138 & 0,02118 & 47,19791 & 137,985 & 1,608 \\
\hline 4000 & 66 & 0 & 132 & 0,01925 & 51,94164 & 131,988 & 1,397 \\
\hline 4200 & 63 & 0 & 126 & 0,01750 & 57,12702 & 125,991 & 1,213 \\
\hline 4400 & 60 & 0 & 120 & 0,01591 & 62,85184 & 119,993 & 1,050 \\
\hline 4600 & 57 & 0 & 114 & 0,01446 & 69,16811 & 113,994 & 0,906 \\
\hline 4800 & 55 & 0 & 110 & 0,01337 & 74,80074 & 109,995 & 0,809 \\
\hline 5000 & 53 & 0 & 106 & 0,01237 & 80,85841 & 105,996 & 0,721 \\
\hline
\end{tabular}
radius of the circular arc

We assume that the analysis will be carried out for the train speed of $V=140 \mathrm{~km} / \mathrm{h}$. In order to maintain the permissible value of unbalanced acceleration $a_{\text {dop }}=0,85 \mathrm{~m} / \mathrm{s}^{2}$, in further calculations, we assume the initial radius of the circular arc $R=1800 \mathrm{~m}$. Assuming the permissible value of the acceleration increment $\psi_{\text {dop }}=0,3 \mathrm{~m} / \mathrm{s}^{3}$ (as for single transition curves with the curvature linear), we get - as a starting point - the lengths of the extreme sections $l_{1}=$ $146 \mathrm{~m}$.

The analysis of the radius of the circular arc was carried out with the assumption that the length $l_{2}=0$. This means that the central part (i.e. the circular arc itself) does not appear in the turnout path, and the $R$ parameter refers only to the extreme sections. The adopted assumption obviously leads to the shortening of the entire junction (i.e. the value of $l_{\mathrm{k}}$ ). Increasing the radius $R$ makes it possible to reduce the length of the nonlinear curvature sections. The results of this operation are presented in Table 2.

For the assumed $R=1800 \mathrm{~m}$ and $l_{1}=146 \mathrm{~m}$, we obtain a turnout with a length of $l_{\mathrm{k}}=$ $292 \mathrm{~m}$, slope 1:10.53595, and end elevation of $15.177 \mathrm{~m}$. Increasing the radius $\mathrm{R}$ shortens the entire turnout and reduces both its end elevation $y\left(l_{\mathrm{k}}\right)$, and a $1: n$ skew (i.e. increasing the value of $n$ ). Therefore, it is a very beneficial operation from the point of view of the executive 
practice. However, since design considerations prevent the turnout end elevation and the turnout haunch not being too small, there is an upper limit for which the $R$ value should not exceed.

\section{Obtaining the required final ordinate of the turnout track}

Tab. 3. Summary of the values characteristic for the generated variants without the central zone to obtain the final ordinate of $2 \mathrm{~m}$

\begin{tabular}{|c|c|c|c|c|c|c|c|}
\hline$R$ & $l_{1}$ & $l_{2}$ & $l_{\mathrm{k}}$ & $\Theta\left(l_{\mathrm{k}}\right)$ & $n$ & $x\left(l_{\mathrm{k}}\right)$ & $y\left(l_{\mathrm{k}}\right)$ \\
\hline [m] & {$[\mathrm{m}]$} & [m] & [m] & [rad] & & [m] & [m] \\
\hline 1800 & 146 & 0 & 292 & 0,09463 & 10,53595 & 291,362 & 15,177 \\
\hline 2200 & 119 & 0 & 238 & 0,06311 & 15,82530 & 237,769 & 8,256 \\
\hline 2600 & 101 & 0 & 202 & 0,04535 & 22,04995 & 201,899 & 5,034 \\
\hline 3000 & 88 & 0 & 176 & 0,03422 & 29,20937 & 175,950 & 3,312 \\
\hline 3400 & 77 & 0 & 154 & 0,02642 & 37,83906 & 153,974 & 2,238 \\
\hline 3500 & 75 & 0 & 150 & 0,02500 & 39,99167 & 149,977 & 2,063 \\
\hline 3600 & 73 & 0 & 146 & 0,02366 & 42,26217 & 145,980 & 1,900 \\
\hline 3700 & 71 & 0 & 142 & 0,02239 & 44,66055 & 141,983 & 1,748 \\
\hline 3510 & 74,48 & 0 & 148,96 & 0,02476 & 40,38610 & 148,938 & 2,028 \\
\hline 3520 & 74,26 & 0 & 148.52 & 0,02461 & 40,62124 & 148,498 & 2,010 \\
\hline 3530 & 74,05 & 0 & 148,1 & 0,02447 & 40,85226 & 148,078 & 1,993 \\
\hline 3540 & 73,84 & 0 & 147,68 & 0,02433 & 41,08460 & 147,659 & 1,976 \\
\hline 3525 & 74,16 & 0 & 148,32 & 0,02454 & 40,73384 & 148,298 & 2,0020 \\
\hline 3526 & 74,14 & 0 & 148,28 & $\mathbf{0 , 0 2 4 5 3}$ & 40,75640 & 148,258 & 2,0004 \\
\hline 3527 & 74,12 & 0 & 148,24 & 0,02452 & 40,77897 & 148,218 & 1,9988 \\
\hline 3528 & 74,1 & 0 & 148,2 & 0,02450 & 40,80155 & 148,178 & 1,9970 \\
\hline 3526 & 74,133 & 0 & 148,266 & 0,02453 & 40,76025 & 148,244 & 2,000049 \\
\hline 3526 & 74,132 & 0 & 148,264 & 0,02453 & 40,76080 & 148,242 & 1,999995 \\
\hline 3526 & 74,131 & 0 & 148,262 & 0,02453 & 40,76135 & 148,240 & 1,999941 \\
\hline
\end{tabular}

We assume obtaining the final elevation $y\left(2 l_{1}+l_{2}\right)=2 \mathrm{~m}$. A turnout with such an end elevation may be used in the connection of parallel tracks with a $4 \mathrm{~m}$ spacing. The procedure here is iterative. Table 3 presents variants without the central zone (for $l_{2}=0$ ).

For the input values of $R=1800 \mathrm{~m}$ and $l_{1}=146 \mathrm{~m}$, we obtain a turnout with a length of $l_{\mathrm{k}}=$ $292 \mathrm{~m}$, slope $1: 10.53595$, and the final ordinate of the turning track equal to $15,177 \mathrm{~m}$. Thus, the final ordinate significantly deviates from the required value of $2 \mathrm{~m}$. it turns out that the basic method of its reduction is to increase the $\mathrm{R}$ radius. This makes it possible to reduce the length of the outermost sections. In an iterative way, we arrive at the radius $l_{\mathrm{k}}=292 \mathrm{~m} \mathrm{~m}$ and corresponding length $l_{1} \in\langle 73 ; 75\rangle \mathrm{m}$, for which the end elevation is in the range $R \in\langle 3500 ; 3600\rangle \mathrm{m}$. Further correcting the values of $R$ and $l_{1}$, we obtain the required end elevation; The finally adopted geometrical layout of the turnout has a radius of $R=3526 \mathrm{~m}$ and the lengths of sections of variable curvature $l_{1}=74,133 \mathrm{~m}$.

The curve of the curvature along the length of the determined turnout path is shown in Figure 6, and the plot of the turn track ordinate in the rectangular coordinate system in Fig. 7.

The analysis carried out further shows that obtaining the assumed final ordinate when introducing the central zone (i.e. the segment of the circular arc) results in the elongation of the entire turnout in each case in relation to the situation presented in Table 3. Therefore, it does not seem advisable to prefer this solution. 


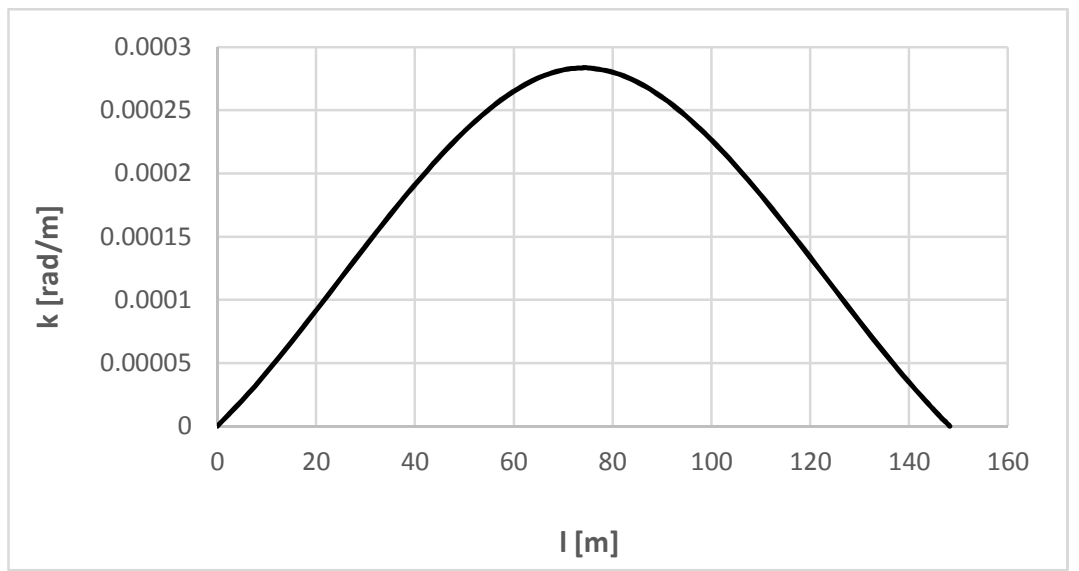

6. The curve of curvature along the length of the designated reversal track of the turnout $\left(R=3526 \mathrm{~m}, l_{1}=74.133 \mathrm{~m}, l_{2}=0\right)$

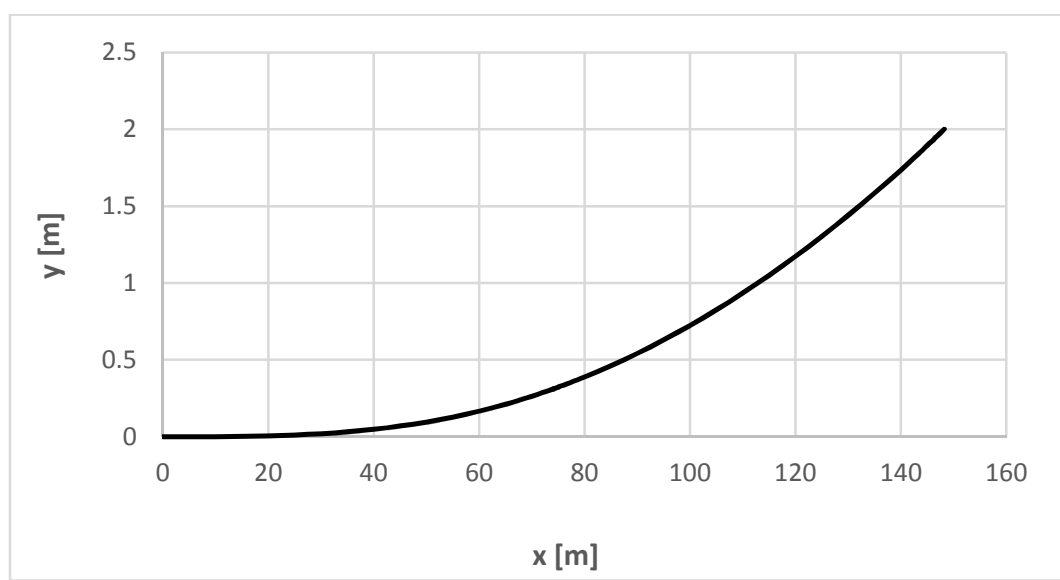

7. The plot of horizontal ordinates along the length of the designated turning track of the turnout $\left(R=3526 \mathrm{~m}, l_{1}=74.133 \mathrm{~m}, l_{2}=0\right.$, on the contaminated scale)

\section{Summary}

In the turning track of a typical railway (ordinary) turnout, a single circular arc without transition curves is used. As a result, there are places of rapid, abrupt change in the ordinates of the curvature plot at the beginning and end of the turnout. Recently, in some countries, in order to smooth the curve of curvature in these regions, the so-called 'Sections of clothoid' on either side of the circular arc in which the curvature varies linearly.

As a result of the dynamic analysis carried out in $[16,17]$, it was shown that the turnout return path with a non-linear course of curvature in the initial zone and the end zone as well as zero curvature values at the extreme points of the geometric system has the most favorable properties. At the same time, doubts arose as to whether the application of the so-called "Clothoid sections" with non-zero curvature values at the start and endpoints of the return path.

This paper presents the analytical method of solving the problem, which is general and complete. The model adopted was the solution with a circular arc in the middle zone, and non-linear curvature sections of the same length in the extreme zones. The most advantageous type of curvature was selected from the point of view of kinematic conditions. The analytical record of the curvature and the angle of the tangent slope along the length of the turnout return track and the Cartesian coordinates of that track was presented.

The final part of the work is devoted to the analysis of the geometric parameters of the return track for a given train speed. The proposed design method made it possible to analyze the value of the circular arc radius and to obtain the required final ordinate of the return track. 
The criterion of minimizing the length of the entire turnout at a given final ordinate of its turn track was followed.

\section{Source materials}

[1] Alfi S., Bruni S.: Mathematical modelling of train-turnout interaction. Vehicle System Dynamics, Vol. 47, No. 5, pp. 551-574, 2009

[2] Bugarin M. R., García Díaz-de-Villegas J. M.: Improvements in railway switches. Proceedings of the Institution of Mechanical Engineers, Part F: Rail and Rapid Transit, Vol. 216, No. 4, pp. 275-286, 2002

[3] Bugarin M., Orro A., Novales M.: Geometry of high speed turnouts. Transportation Research Record: Journal of the Transportation Research Board, Dec. 2011, Vol. 2261, pp. 64-72, 2011

[4] Esveld C.: Modern railway track, second ed. MRT-Productions, Zaltbommel, Netherlands, 2001

[5] Koc W.: Design of rail-track geometric systems by satellite measurement. Journal of Transportation Engineering, Vol 138, No. 1, pp. 114-122, 2012

[6] Koc W.: Design of reverse curves adapted to the satellite measurements. Advances in Civil Engineering, Vol. 2016, Article ID 6503962

[7] Koc W.: The analytical design method of railway route's main directions intersection area. Open Engineering, Vol. 6, No. 1, pp. 1-9, 2016

[8] Koc W.: Kształtowanie toru zwrotnego rozjazdu z odcinkami krzywizny liniowej. Problemy Kolejnictwa, Tom 61, Zesz.. 174, s. 39-46, 2017

[9] Koc W.: Modelowanie zmiennej krzywizny na długości toru zwrotnego rozjazdu. Przegląd Komunikacyjny, Rok 72, Nr 8, s. 9-12, 2017

[10] Koc W.: Shaping of the turnout diverging track with variable curvature sections. International Journal of Rail Transportation, Vol. 5, No. 4, pp. 229-249, 2017

[11] Koc W.: Zastosowanie odcinków nieliniowej krzywizny w torze zwrotnym rozjazdu kolejowego. Przegląd Komunikacyjny, Rok 72, Nr 7, s. 27-31, 2017

[12] Koc W.: Rozjazdy z nieliniową krzywizną toru zwrotnego dla różnych prędkości jazdy pociągów. Problemy Kolejnictwa, Tom 62, Zesz.. 181, s. 33-41, 2018

[13] Koc W.: Optimum shape of turnout diverging track with segments of variable curvature. Journal of Transportation Engineering, Part A: Systems, Vol. 145, Iss. 1, pp. 04018077, 2019

[14] Koc W.: New transition curve adapted to railway operational requirements. Journal of Surveying Engineering, Vol. 145, Iss. 3, pp. 04019009, 2019

[15] Koc W.: Wygładzona krzywa przejściowa dla dróg kolejowych. Przegląd Komunikacyjny, Rok 74, Nr 7, s. 12-17, 2019

[16] Koc W., Palikowska K.: Dynamic analysis of the turnout diverging track for HSR with variable curvature sections. World Journal of Engineering and Technology, Vol. 5, pp. 42-57, 2017

[17] Koc W., Palikowska K.: Wyznaczanie optymalnej krzywizny toru zwrotnego w rozjazdach dla kolei dużych prędkości na podstawie analizy dynamicznej. Przegląd Komunikacyjny, Rok 72, Nr 10, s. 2-7, 2017

[18] Lichtberger B.: Track Compendium. Formation, Permanent Way, Maintenance, Economics. Eurailpress Tetzlaff-Hestra GmbH \& Co., Hamburg, Germany, 2005

[19] Maxima, a Computer Algebra System. [Dostęp: 30 marca 2020], dostępny na http://maksima.sourceforge.net

[20] Ping W.: Design of high-speed railway turnouts. Theory and Applications. Elsevier Science \& Technology, Oxford, United Kingdom, 2015 
[21] Ping W., Xueyi L.: Computing theories and design methods of CWR turnout. Southwest Jiaotong University Press, Chengdu, China, 2007

[22] Plank B.: Linie dużych prędkości realizowane przez VAE. Prezentacja firmy Voestalpine GmbH, 2007

[23] Prasad A.: Turnout design: higher diverging speed in the same footprint. Proceedings of the AREMA 2011 Annual Conference, September 18-21, 2011, Minneapolis, USA

[24] Sadeghi J., Masnabadi A., Mazraeh A.: Correlations among railway track geometry, safety and speeds. Proceedings of the Institution of Civil Engineers - Transport, Vol. 169, No. 4, pp. 219-229, 2016

[25] Technical Memorandum: Alignment design standards for high-speed train operation. Parsons Brinckerhoff for the California High-Speed Rail Authority, USA, 2009

[26] Weizhu F.: Major technical characteristics of high-speed turnout in France. Journal of Railway Engineering Society, Vol. 26, No. 9, pp. 18-35, 2009 